\title{
Pyrrolo[3,2-b]pyrrole-Based Copolymers as Donor Materials for Organic Photovoltaics
}

\author{
Suhee Song, Seo-Jin Ko, ${ }^{\dagger}$ Hyunmin Shin, Youngeup Jin, ${ }^{\star}$ Il Kim, ${ }^{\S}$ Jin Young Kim, ${ }^{\dagger, *}$ and Hongsuk Suh ${ }^{*}$ \\ Department of Chemistry and Chemistry Institute for Functional Materials, Pusan National University, \\ Busan 609-735, Korea. ${ }^{*}$ E-mail: hssuh@pusan.ac.kr \\ ${ }^{\dagger}$ Interdisciplinary School of Green Energy, Ulsan National Institute of Science and Technology, \\ Ulsan 689-798, Korea. ${ }^{*}$ E-mail: jykim@unist.ac.kr \\ ${ }^{\star}$ Department of Industrial Chemistry, Pukyong National University, Busan 608-739, Korea \\ ${ }^{\S}$ The WCU Center for Synthetic Polymer Bioconjugate Hybrid Materials, Department of Polymer Science \\ and Engineering, Pusan National University, Busan 609-735, Korea \\ Received June 7, 2013, Accepted August 30, 2013
}

\begin{abstract}
A new accepter unit, pyrrolo[3,2-b]pyrrole-2,5-dione, was prepared and utilized for the synthesis of the conjugated polymers containing electron donor-acceptor pair for OPVs. Pyrrolo[3,2-b]pyrrole-2,5-dione unit, regioisomer of the known pyrrolo[3,4-c]pyrrole-1,4-dione, is originated from the structure of stable synthetic pigment. The new conjugated polymers with 1,4-diphenylpyrrolo[3,2-b]pyrrole-2,5-dione, thiophene and carbazole were synthesized using Suzuki polymerization to generate P1 and P2. The solid films of P1 and P2 show absorption bands with maximum peaks at about 377, 554 and 374, $542 \mathrm{~nm}$ and the absorption onsets at 670 and $674 \mathrm{~nm}$, corresponding to band gaps of 1.85 and $1.84 \mathrm{eV}$, respectively. To improve the hole mobility of the polymer with 1,4-bis(4-butylphenyl)-pyrrolo[3,2-b]-pyrrole-2,5-dione unit, which was previously reported by us, the butyl group at the 4-positions of the $N$-substituted phenyl group was substituted with hydrogen and methyl group. The field-effect hole mobility of $\mathbf{P 2}$ is $9.6 \times 10^{-5} \mathrm{~cm}^{2} / \mathrm{Vs}$. The device with $\mathrm{P} 2: \mathrm{PC}_{71} \mathrm{BM}(1: 2)$ showed $V_{\mathrm{OC}}$ value of $0.84 \mathrm{~V}, J_{\mathrm{SC}}$ value of $5.10 \mathrm{~mA} / \mathrm{cm}^{2}$, and $F F$ of 0.33 , giving PCE of $1.42 \%$.
\end{abstract}

Key Words : Polymer-based solar cells, Photovoltaic cells, Pyrrolo[3,2-b]pyrrole-2,5-dione

\section{Introduction}

In recent years, the development of efficient polymerbased solar cells has become an active area of research due to their potential as alternative source of green energy. ${ }^{1-3}$ Organic photovoltaics (OPVs) with bulk heterojunction (BHJ) architecture have attracted substantial attentions due to its possibility to be renewable clean energy for low-cost, lightweight, printable, and flexible large area devices. ${ }^{4,5}$ Conjugated polymers as the donor with the fullerene derivative PCBM as the acceptor have achieved impressive values of power conversion efficiency (PCE) near $8 \%{ }^{6}$ to $\geq 10 \%{ }^{7}$ in bulk heterojunction (BHJ) devices. ${ }^{6,7}$

To obtain low bandgap conjugated polymers with planar molecular geometries, various types of aromatic heterocycles have been widely investigated in OPVs. ${ }^{8-10}$ Semiconducting copolymers with diketopyrrolopyrrole units are emerging as interesting materials for optoelectronic applications in fieldeffect transistors (FETs) ${ }^{11}$ and organic photovoltaic cells. ${ }^{12}$ The pyrrolo[3,4-c]pyrrole-1,4-dione (DPP) chromophore has been primarily known in commercial high-performance pigments with heat stability and high and balanced hole and electron mobilities for optoelectronic applications. The DPP unit constitutes a planar moiety capable of providing $\pi-\pi$ stacking in the solid state to generate efficient charge transport. $^{13}$ The pyrrolo[3,2- $\left.b\right]$ pyrrole-2,5-dione (iDPP) exhibiting absorption in the near IR range, the structure of a natural dye found in lichens, ${ }^{14}$ is the regioisomer of the known DPP which has been used as the electron rich unit. ${ }^{15}$ In our previous study, new electron deficient unit, 1,4-bis(4butylphenyl)-pyrrolo[3,2- $b]$-pyrrole-2,5-dione, has been designed and utilized for the efficient ICT to generate polymer with low band gap. ${ }^{16}$

In this paper, we reported the synthesis and characterization of polymers with iDPP for OPV device. At the 4positions of the $N$-substituted phenyl groups of 1,4-bis(4butylphenyl)-pyrrolo[3,2- $b]$-pyrrole-2,5-dione unit, the butyl group was substituted with hydrogen or methyl group to improve the hole mobility. The low bandgap conjugated polymers were synthesized by Suzuki coupling reaction of iDPP as the electron poor unit and carbazole as the electron rich unit with thiophene as the bridge. The photovoltaic properties of the polymers were investigated by fabrication of the polymer solar cells with the configuration of ITO/ PEDOT:PSS/polymer:PCBM/A1.

\section{Results and Discussion}

Synthesis and Characterization. The general synthetic routes of the monomers and polymers are outlined in Scheme 1. In the first step, ethyl 2-thiopheneacetate (1) was brominated with $\mathrm{N}$-bromosuccinimide (NBS) to generate ethyl 2-(5-bromo-2-thienyl)acetate (2). The aniline (3) and $p$-toluidine (4) were treated with oxalyl chloride (6) and $\mathrm{PCl}_{5}$ 
in toluene to provide diphenylethanediimidoyl dichloride (6) and $N, N^{\prime}$-bis(4-methylphenyl)ethanediimidoyl dichloride (7), respectively. Ethyl 2-(5-bromo-2-thienyl)acetate (2) and compound $\mathbf{6}$ (or compound 7) were coupled using

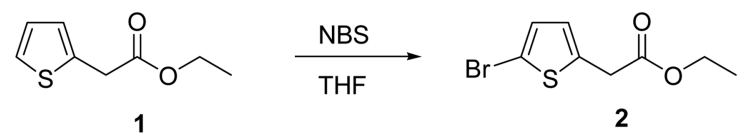<smiles>[R]c1ccc(N=C(Cl)C(Cl)=Nc2ccc([R])cc2)cc1</smiles><smiles>[R]c1ccc(N=C(Cl)C(Cl)=Nc2ccc([R])cc2)cc1</smiles>

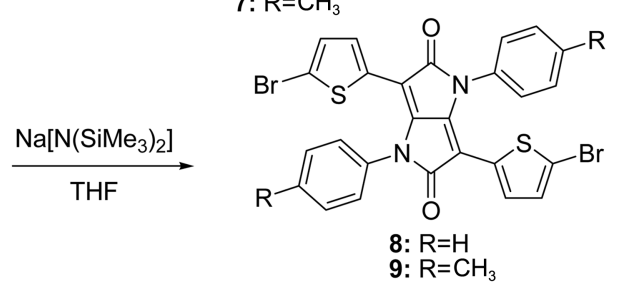<smiles>[R][R]([H])=C</smiles>

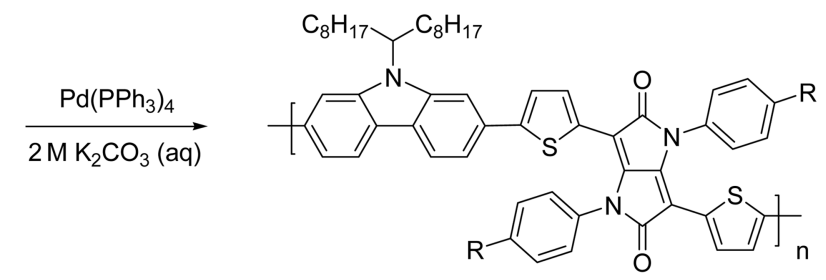

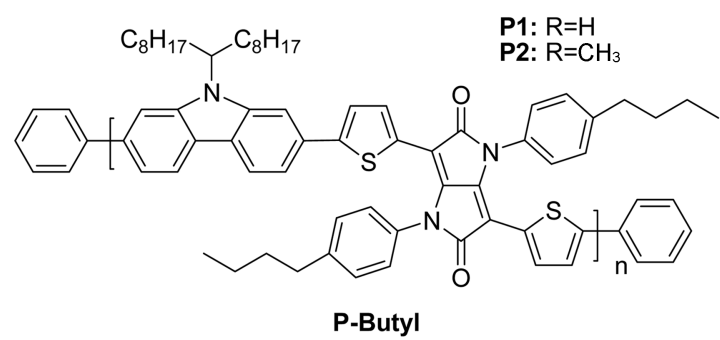

Scheme 1. Synthetic route for the synthesis of the monomer and polymer.
$\mathrm{Na}\left[\mathrm{N}\left(\mathrm{SiMe}_{3}\right)_{2}\right]$ to form 3,6-bis $\{5$-[4-(diphenylamino)phenyl]-2-thienyl\}-1,4-diphenylpyrrolo[3,2-b]pyrrole-2,5-dione (8) (or 3,6-bis $\{5$-[4-(diphenylamino)phenyl]-2-thienyl $\}$-1,4bis(4-methylphenyl)pyrrolo[3,2-b]pyrrole-2,5-dione (9)). Compound $\mathbf{8}$ (or compound 9 ), as electron-accepting moiety, and 2,7-bis $\left(4^{\prime}, 4^{\prime}, 5^{\prime}, 5^{\prime}\right.$-tetramethyl-1',3',2'-dioxaborolan-2'yl)- $N$-9"-heptadecanylcarbazole (10), ${ }^{10}$ as electron-donating unit, were co-polymerized through Suzuki coupling reaction with $\operatorname{Pd}(0)$-catalyst to yield poly $(N-9$-heptadecanyl-2,7carbazole-alt-3,6-bis $\{5$-[4-(diphenylamino)phenyl]-2-thienyl\}-1,4-diphenylpyrrolo[3,2-b]pyrrole-2,5-dione) (P1) (or poly $(N$-9-heptadecanyl-2,7-carbazole-alt-3,6-bis $\{5$-[4-(diphenylamino)phenyl]-2-thienyl $\}$-1,4-bis(4-methylphenyl)pyrrolo[3,2-b] pyrrole-2,5-dione) (P2)). The structures and purities of the monomers were confirmed by ${ }^{1} \mathrm{H}-\mathrm{NMR},{ }^{13} \mathrm{C}$ NMR, and HRMS. The synthesized polymers were soluble in various organic solvents such as chloroform, chlorobenzene, tetrahydrofuran (THF), dichloromethane and o-dichlorobenzene (ODCB).

Table 1 summarizes the polymerization results including molecular weight, polydispersity index (PDI) and thermal stability of the polymers. The weight-average molecular weight $\left(M_{\mathrm{w}}\right)$ of 16700 and 32800 with polydispersity index (PDI, $M_{\mathrm{w}} / M_{\mathrm{n}}$ ) value of 3.0 and 2.4 of the $\mathbf{P 1}$ and $\mathbf{P 2}$ were determined by gel permission chromatography (GPC), respectively. The thermal properties of the polymers were characterized by both differential scanning calorimetry (DSC) and thermal gravimetric analysis (TGA). TGA was performed with TGA 2950 in a nitrogen atmosphere at a heating rate of $10{ }^{\circ} \mathrm{C} / \mathrm{min}$ to $600{ }^{\circ} \mathrm{C}$. The DSC analysis was performed under a nitrogen atmosphere $(50 \mathrm{~mL} / \mathrm{min})$ on a DSC 2920 at heating rate of $10{ }^{\circ} \mathrm{C} / \mathrm{min}$. The decomposition temperatures ( $T_{\mathrm{d}}, 5 \%$ weight loss) are 407 and $388^{\circ} \mathrm{C}$ for $\mathbf{P 1}$ and $\mathbf{P} 2$ under

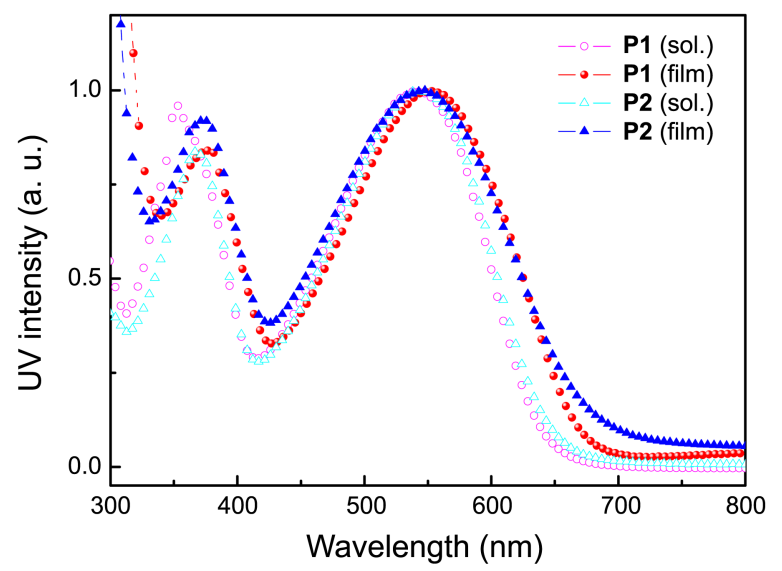

Figure 1. UV-visible absorption spectra of polymer in chloroform solution and the solid state.

Table 1. Polymerization Result and Properties of Polymer

\begin{tabular}{cccccccc}
\hline Polymer & $M_{\mathrm{n}}{ }^{a}$ & $M_{\mathrm{w}}{ }^{a}$ & PDI $^{a}$ & DSC $\left(T_{\mathrm{g}}\right)$ & ${\text { TGA }\left(T_{\mathrm{d}}\right)^{b}}^{b}$ & $\lambda_{\max }(\mathrm{sol})$. & $\lambda_{\max }(\mathrm{film})$ \\
\hline P1 & 5500 & 16700 & 3.0 & 116 & 407 & 352,540 & 377,554 \\
P2 & 13600 & 32800 & 2.4 & 95 & 388 & 367,541 & 374,542 \\
\hline
\end{tabular}

${ }^{a}$ Molecular weight $\left(M_{\mathrm{w}}\right)$ and polydispersity (PDI) of the polymers were determined by gel permeation chromatography (GPC) in THF using polystyrene standards. ${ }^{b}$ Onset decomposition temperature ( $5 \%$ weight loss) measured by TGA under $\mathrm{N}_{2}$. 
$\mathrm{N}_{2}$. The $T_{\mathrm{d}}$ value of $\mathbf{P} \mathbf{1}$ is higher than that of $\mathbf{P} \mathbf{2}$ with two methyl groups introduced at 4-positions of the $\mathrm{N}$-substituted phenyl groups. The $\mathbf{P 1}$ and $\mathbf{P 2}$ showed good thermal stability with glass transition temperature $\left(T_{\mathrm{g}}\right)$ values of 116 and $95^{\circ} \mathrm{C}$, using DSC performed at a temperature range of 30 to $200{ }^{\circ} \mathrm{C}$. The $T_{\mathrm{g}}$ value of $\mathbf{P 1}$ is higher than that of $\mathbf{P 2}$ caused by crystallinity coming from the removal of the methyl groups. The high thermal stability of the resulting polymers prevents the deformation of the polymer morphology and is important for organic photovoltaics (OPVs) application.

Optical Properties. The optical properties of chloroform solution and films of the polymers were investigated by UVvis absorption spectroscopy as shown in Figure 1. Uniform films were prepared on quartz plate by spin-casting from their chloroform solution at room temperature. The absorption spectra of $\mathbf{P 1}$ and $\mathbf{P 2}$ exhibited maximum peaks at about 352,540 and $367,541 \mathrm{~nm}$ in solution, respectively. The short wavelength absorption peak of $\mathbf{P 1}$ in solution was blue shifted about $16 \mathrm{~nm}$ as compared with that of the polymer based on pyrrolo[3,2-b]pyrrole-2,5-dione (iDPP) with butyl chains (P-Butyl) ${ }^{16}$ caused by lower molecular weight. The solid films of $\mathbf{P 1}$ and $\mathbf{P 2}$ show absorption bands with maximum peaks at about 377,554 and $374,542 \mathrm{~nm}$ and the absorption onsets at 670 and $674 \mathrm{~nm}$, corresponding to band gaps of 1.85 and $1.84 \mathrm{eV}$, respectively. The absorption peaks of $\mathbf{P 1}$ in film were red shifted as compared with the case of P-Butyl because the alkyl chain, which prevent $\pi-\pi^{*}$ stacking of the polymer backbone, was removed. In both cases of $\mathbf{P 1}$ and $\mathbf{P 2}$, the short wavelength absorption maxima and the absorption onsets of the films were red shifted as compared to the solution state. The long wavelength absorption peaks of the films show higher fwhm (full width at half maximum) as compared to the cases of the solution state. The short-wavelength absorption peak has been ascribed to a delocalized excitonic $\pi-\pi^{*}$ transition in the conjugated chain and the long-wavelength absorption peak attributed to the intramolecular charge transfer (ICT) between the carbazole and iDPP units. ${ }^{17}$

Electrochemical Properties. The electrochemical property of the polymer was determined from the bandgap estimated from the absorption onset wavelength, and the HOMO energy level which was estimated from the cyclic voltammetry (CV). The $\mathrm{CV}$ was performed with a solution of tetrabutylammonium tetrafluoroborate $\left(\mathrm{Bu}_{4} \mathrm{NBF}_{4}\right)(0.10 \mathrm{M})$ in acetonitrile at a scan rate of $100 \mathrm{mV} / \mathrm{s}$ at room temperature under argon atmosphere. A platinum electrode $(\sim 0.05$ $\mathrm{cm}^{2}$ ) coated with a thin polymer film was used as the working electrode. Pt wire and $\mathrm{Ag} / \mathrm{AgNO}_{3}$ electrode were used as

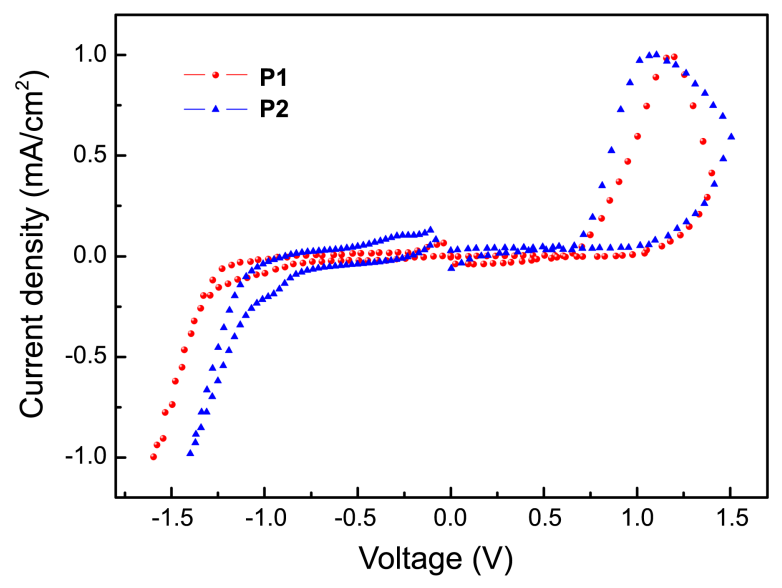

Figure 2. Electrochemical properties of polymers.

the counter electrode and reference electrode, respectively. The energy level of the $\mathrm{Ag} / \mathrm{AgNO}_{3}$ reference electrode (calibrated by the $\mathrm{Fc} / \mathrm{Fc}^{+}$redox system) was $4.8 \mathrm{eV}$ below the vacuum level. ${ }^{18}$ The CV spectra are shown in Figure 2, and the oxidation potentials derived from the onsets of electrochemical p-doping are summarized in Table 2. HOMO and LUMO levels were calculated according to the empirical formula $\left(\mathrm{E}_{\mathrm{HOMO}}=-\left(\left[\mathrm{E}_{\mathrm{onset}}\right]^{\mathrm{ox}}+4.8\right) \mathrm{eV}\right)$ and $\left(\mathrm{E}_{\mathrm{LUMO}}=\right.$ $\left.-\left(\left[\mathrm{E}_{\text {onset }}\right]^{\text {red }}+4.8\right) \mathrm{eV}\right)$, respectively. The polymers, $\mathbf{P 1}$ and P2, exhibited the absorption onset wavelengths of 670 and $674 \mathrm{~nm}$ in solid thin films, which correspond to band gaps of 1.85 and $1.84 \mathrm{eV}$, respectively. The polymers exhibit irreversible processes in an oxidation scan. The oxidation onsets of the $\mathbf{P 1}$ and $\mathbf{P 2}$ were estimated to be 0.66 and $0.67 \mathrm{~V}$, which correspond to HOMO energy levels of -5.46 and $-5.47 \mathrm{eV}$, respectively. The reduction potential onsets of $\mathbf{P 1}$ and $\mathbf{P} \mathbf{2}$ are -1.26 and $-1.15 \mathrm{~V}$, which correspond to LUMO energy levels of -3.54 and $-3.65 \mathrm{eV}$, respectively. The electrochemical bandgaps, calculated from cyclic voltammetry data, are about 1.92 and $1.82 \mathrm{eV}$.

FET and Photovoltaic Properties. The field-effect carrier mobilities of the polymers were measured by fabricating thin film field-effect transistors (FETs) using the top-contact geometry. Figure 3 shows the FET transfer characteristics of the polymer devices of the OTS-modified $\mathrm{SiO}_{2}$. Hole mobilities of the $\mathbf{P 1}$ and $\mathbf{P 2}$ were calculated from the transfer characteristics of the OFETs. To improve the hole mobility of the polymer with 1,4-bis(4-butylphenyl)-pyrrolo[3,2-b]pyrrole-2,5-dione unit, which was previously reported by us, the butyl group at the 4-positions of the $\mathrm{N}$-substituted phenyl group was substituted with hydrogen and methyl group to provide $\mathbf{P 1}$ and $\mathbf{P 2}$. The field-effect hole mobilities of $\mathbf{P 1}$ and $\mathbf{P 2}$ are $1.6 \times 10^{-5}$ and $9.6 \times 10^{-5} \mathrm{~cm}^{2} / \mathrm{Vs}$, respectively.

Table 2. Electrochemical potentials and energy levels of the polymer

\begin{tabular}{ccccccc}
\hline Polymer & Optical band gap $^{a}(\mathrm{eV})$ & $\mathrm{HOMO}^{b}(\mathrm{eV})$ & $\mathrm{LUMO}^{c}(\mathrm{eV})$ & $\mathrm{E}_{\mathrm{ox}}{ }^{d}(\mathrm{~V})$ & $\mathrm{E}_{\text {red }}{ }^{d}(\mathrm{~V})$ & $\mathrm{Chemical} \mathrm{band} \mathrm{gap}^{e}(\mathrm{eV})$ \\
\hline P1 & 1.85 & -5.46 & -3.54 & 0.66 & -1.26 & 1.92 \\
P2 & 1.84 & -5.47 & -3.65 & 0.67 & -1.15 & 1.82 \\
\hline
\end{tabular}

${ }^{a}$ Optical energy band gap was estimated from the onset wavelength of the optical absorption. ${ }^{b}$ Calculated from the oxidation potentials. ${ }^{c}$ Calculated from the reduction potentials. ${ }^{d}$ Onset oxidation and reduction potential measured by cyclic voltammetry. ${ }^{e}$ Calculated from the $\mathrm{E}_{\mathrm{ox}}$ and $\mathrm{E}_{\mathrm{red}}$. 

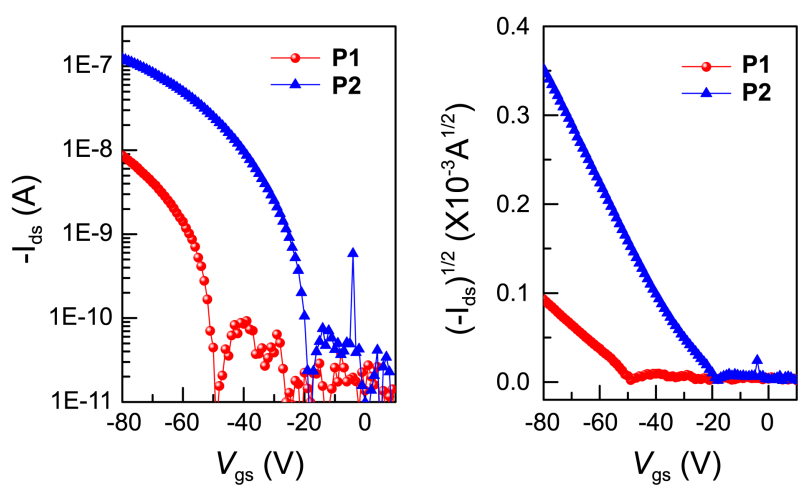

Figure 3. Transfer Characteristics of PCDTPPDB-based Topcontact OFETs.

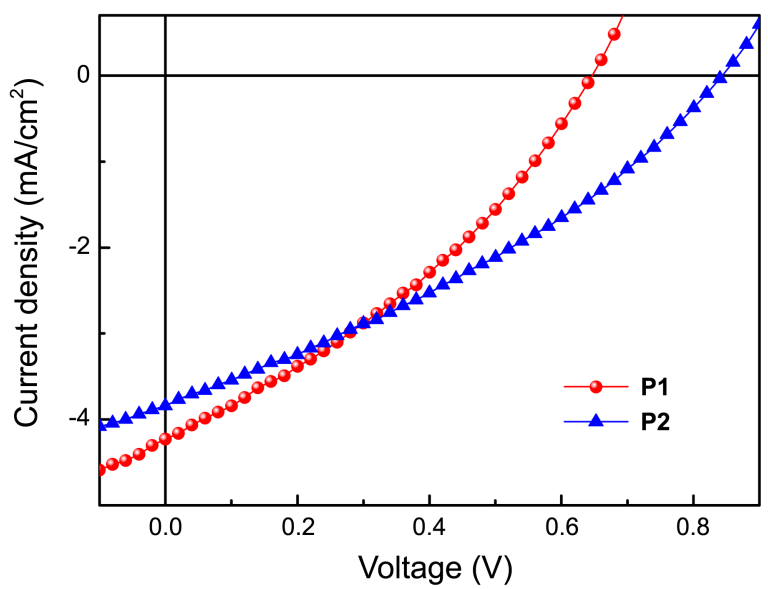

Figure 4. Current density-potential characteristics of the polymer solar cell under the illumination of AM $1.5,100 \mathrm{~mW} / \mathrm{cm}^{2}$.

Through this modification, the mobility was increased in case of $\mathbf{P 2}$ but was decreased in case of $\mathbf{P 1}$ caused by its relatively poor solubility.

The OPVs were fabricated by spin-casting of ODCB solution of PCBM/polymers. All polymers were applied as donors into a conventional BHJ type OPV device with $\mathrm{PC}_{71} \mathrm{BM}$ as acceptor, which has been widely used for this purpose. Typical $J-V$ characteristics of devices with the configuration of ITO/PEDOT:PSS (40 nm)/polymer: $\mathrm{PC}_{71} \mathrm{BM}$ $(1: 2)(80 \mathrm{~nm}) /$ without or with $\mathrm{TiO}_{\mathrm{x}}(10 \mathrm{~nm}) / \mathrm{Al}(100 \mathrm{~nm})$ under AM $1.5 \mathrm{G}$ irradiation $\left(100 \mathrm{~mW} / \mathrm{cm}^{2}\right)$ are depicted in Figure 4 . The photovoltaic parameters for all the polymers, including open circuit voltage $\left(V_{\mathrm{OC}}\right)$, short circuit current density $\left(J_{\mathrm{SC}}\right)$, fill factor $(F F)$, and power conversion efficiency (PCE) are summarized in Table 3. The device of P1:PC ${ }_{71} \mathrm{BM}(1: 2)$ showed $V_{\mathrm{OC}}$ value of $0.65 \mathrm{~V}, J_{\mathrm{SC}}$ value of $4.23 \mathrm{~mA} / \mathrm{cm}^{2}$, and $F F$ of 0.34 , giving PCE of $0.93 \%$. The device with $\mathbf{P 2}: \mathrm{PC}_{71} \mathrm{BM}(1: 2)$ showed $V_{\mathrm{OC}}$ value of $0.84 \mathrm{~V}$, $J_{\mathrm{SC}}$ value of $5.10 \mathrm{~mA} / \mathrm{cm}^{2}$, and $F F$ of 0.33 , giving PCE of $1.42 \%$. In case of the devices with blending ratio of $1: 2$, the PCE values of the devices were increased caused by the increased current density. However, neither of the processes, using 1,8-diiodooctane (DIO) or thermal treatment, improved the performance in the devices based on the polymer:PCBM (1:2) blend. The incident photon to current efficiency (IPCE)
Table 3. Photovoltaic properties of the polymer

\begin{tabular}{cccccc}
\hline Polymer & $\begin{array}{c}\text { doron: } \\
\text { PCBM }\end{array}$ & $\begin{array}{c}V_{\mathrm{OC}} \\
(\mathrm{V})\end{array}$ & $\begin{array}{c}J_{\mathrm{SC}} \\
\left(\mathrm{mA} / \mathrm{cm}^{2}\right)\end{array}$ & FF & $\begin{array}{c}\text { PCE } \\
(\%)\end{array}$ \\
\hline \multirow{4}{*}{$\mathbf{P 1}$} & $1: 2^{a}$ & 0.76 & 3.11 & 0.37 & 0.87 \\
& $1: 2^{b}$ & 0.65 & 4.23 & 0.34 & 0.93 \\
& $1: 3^{b}$ & 0.66 & 3.58 & 0.36 & 0.85 \\
& $1: 4^{b}$ & 0.65 & 3.92 & 0.33 & 0.86 \\
\hline \multirow{3}{*}{$\mathbf{P 2}$} & $1: 2^{a}$ & 0.84 & 3.84 & 0.33 & 1.06 \\
& $1: 2^{b}$ & 0.84 & 5.10 & 0.33 & 1.42 \\
& $1: 3^{b}$ & 0.81 & 3.00 & 0.31 & 0.75 \\
& $1: 4^{b}$ & 0.82 & 2.30 & 0.31 & 0.58 \\
\hline
\end{tabular}

asing $\mathrm{PC}_{61} \mathrm{BM} .{ }^{b}$ using $\mathrm{PC}_{71} \mathrm{BM}$.

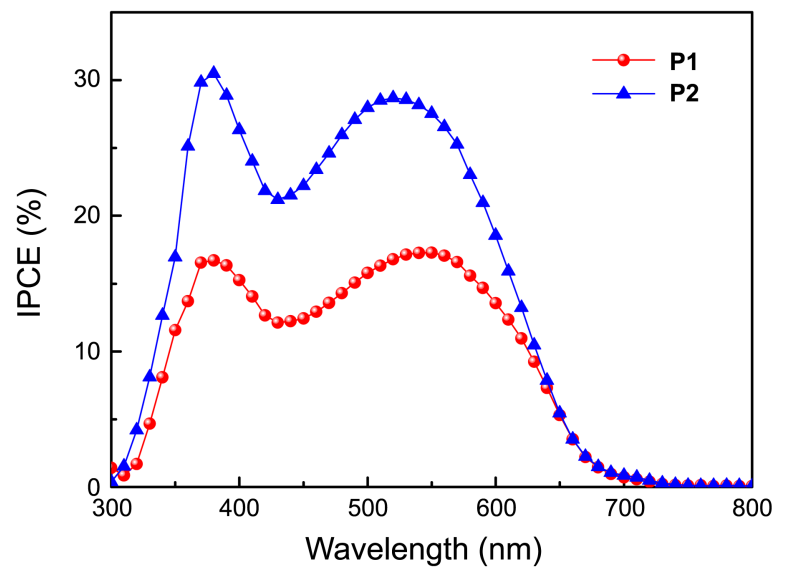

Figure 5. IPCE curve of the polymer solar cells under the illumination of AM 1.5, $100 \mathrm{~mW} / \mathrm{cm}^{2}$.

spectra of the photovoltaic devices from polymer: $\mathrm{PC}_{71} \mathrm{BM}$ blends are presented in Figure 5. The IPCE spectra of the polymers show maxima of $17.3 \%$ at $550 \mathrm{~nm}$ for $\mathbf{P 1}$ and $30.5 \%$ at $380 \mathrm{~nm}$ for $\mathbf{P 2}$.

\section{Conclusions}

The polymers, P1 and P2 utilizing the acceptor unit, diphenylpyrrolo[3,2-b]pyrrole-2,5-dione, were synthesized to show good solubility at room temperature in organic solvents. Pyrrolo[3,2- $b]$ pyrrole-2,5-dione unit, regioisomer of the known pyrrolo[3,4-c]pyrrole-1,4-dione, is originated from the structure of stable synthetic pigment. The solid films of $\mathbf{P 1}$ and $\mathbf{P 2}$ show absorption bands with maximum peaks at about 377,554 and $374,542 \mathrm{~nm}$ and the absorption onsets at 670 and $674 \mathrm{~nm}$, corresponding to band gaps of 1.85 and $1.84 \mathrm{eV}$, respectively. The hole mobility of $\mathbf{P 2}$ is $9.6 \times 10^{-5} \mathrm{~cm}^{2} / \mathrm{Vs}$. The device with $\mathrm{P} 2: \mathrm{PC}_{71} \mathrm{BM}(1: 2)$ showed $V_{\mathrm{OC}}$ value of $0.84 \mathrm{~V}, J_{\mathrm{SC}}$ value of $5.10 \mathrm{~mA} / \mathrm{cm}^{2}$, and $F F$ of 0.33 , giving PCE of $1.42 \%$.

\section{Experimental Section}

General. All reagents were purchased from Aldrich or TCI, and used without further purification. Solvents were purified by normal procedure and handled under moisture- 
free atmosphere. ${ }^{1} \mathrm{H}$ and ${ }^{13} \mathrm{C}$ NMR spectra were recorded with a Varian Gemini-300 (300 MHz) spectrometer and chemical shifts were recorded in ppm units with TMS as the internal standard. Flash column chromatography was performed with Merck silica gel 60 (particle size 230-400 mesh ASTM) with ethyl acetate/hexane or methanol/methylene chloride gradients unless otherwise indicated. Analytical thin layer chromatography (TLC) was conducted using Merck $0.25 \mathrm{~mm}$ silica gel $60 \mathrm{~F}$ pre-coated aluminum plates with fluorescent indicator UV254. High resolution mass spectra (HRMS) were recorded on a JEOL JMS-700 mass spectrometer under electron impact (EI) conditions in the Korea Basic Science Institute (Daegu). The UV-vis absorption spectra were recorded by a Varian 5E UV/VIS/NIR spectrophotometer, while the Oriel InstaSpec IV CCD detection system with xenon lamp was used for the photoluminescence and electroluminescence spectra measurements.

Solar cells were fabricated on an indium tin oxide (ITO)coated glass substrate with the following structure; ITOcoated glass substrate/poly(3,4-ethylenedioxythiophene) (PEDOT:PSS)/small molecule: PCBM/Al. The ITO-coated glass substrate was first cleaned with detergent, ultrasonicated in acetone and isopropyl alcohol, and subsequently dried overnight in an oven. PEDOT:PSS (Baytron PH) was spin-cast from aqueous solution to form a film of $40 \mathrm{~nm}$ thickness. The substrate was dried for $10 \mathrm{~min}$ at $140{ }^{\circ} \mathrm{C}$ in air and then transferred into a glove box to spin-cast the active layer. A solution containing a mixture of small molecule:PCBM in dichlorobenzene solvent with concentration of $7 \mathrm{wt} \% / \mathrm{mL}$ was then spin-cast on top of the PEDOT/PSS layer. The film was dried for $60 \mathrm{~min}$ at $70{ }^{\circ} \mathrm{C}$ in the glove box. The sample was heated at $80^{\circ} \mathrm{C}$ for $10 \mathrm{~min}$ in air. Then, an aluminum (Al, $100 \mathrm{~nm}$ ) electrode was deposited by thermal evaporation in a vacuum of about $5 \times 10^{-7}$ Torr. Current density-voltage $(J-V)$ characteristics of the devices were measured using a Keithley 236 Source Measure Unit. Solar cell performance utilized an Air Mass 1.5 Global (AM $1.5 \mathrm{G})$ solar simulator with an irradiation intensity of 1000 $\mathrm{W} \mathrm{\textrm {m } ^ { 2 }}$. An aperture $\left(12.7 \mathrm{~mm}^{2}\right)$ was used on top of the cell to eliminate extrinsic effects such as cross-talk, waveguiding, shadow effects, etc. The spectral mismatch factor was calculated by comparison of solar simulator spectrum with AM 1.5 spectrum at room temperature. The IPCE is a measure of the photon to electron conversion efficiency at a particular irradiation wavelength (Eq. 1).

$$
\operatorname{IPCE}=\left(1240 \times J_{\mathrm{SC}}\right) /\left(\lambda_{\mathrm{i}} \times \mathrm{P}_{\text {in }}\right)
$$

Synthesis of Ethyl 2-(5-bromo-2-thienyl)acetate (2): Ethyl 2-thiopheneacetate (1) (10 g, $66.66 \mathrm{mmol})$ was brominated with $N$-bromosuccinimide (NBS) (13 g, $73.26 \mathrm{mmol}$ ) in THF $(20 \mathrm{~mL})$ at room temperature. After stirring for $24 \mathrm{~h}$, water $(200 \mathrm{~mL})$ and ethyl acetate $(400 \mathrm{~mL})$ were added. The organic layer was washed with $3 \times 200 \mathrm{~mL}$ of water and concentrated under reduced pressure. The residue was purified by flash column chromatography to give compound 2 as a yellow oil; ${ }^{1} \mathrm{H}$ NMR $\left(300 \mathrm{MHz}, \mathrm{CDCl}_{3}\right) \delta 1.29(\mathrm{t}, 3 \mathrm{H}$, $J=7.1 \mathrm{~Hz}), \delta 3.76$ (s, 2H), $\delta 4.19$ (q, 2H, $J=7.1 \mathrm{~Hz}$ ), $\delta 6.69$ $(\mathrm{d}, 1 \mathrm{H}, J=3.8 \mathrm{~Hz}), \delta 6.90(\mathrm{~d}, 1 \mathrm{H}, J=3.8 \mathrm{~Hz}) ;{ }^{13} \mathrm{C} \mathrm{NMR}(75$ $\left.\mathrm{MHz}, \mathrm{CDCl}_{3}\right) \delta 14.35,36.07,61.59,111.55,127.31,129.66$, 137.09, 170.05; HRMS (EI $\left.I^{+}, \mathrm{m} / \mathrm{z}\right)$ calcd for $\mathrm{C}_{8} \mathrm{H}_{9} \mathrm{BrO}_{2} \mathrm{~S}$ 247.9507, measured 247.9509.

Synthesis of Diphenylethanediimidoyl Dichloride (6): A solution of aniline (3) (54.82 mmol) and oxalyl chloride (5) $(10.9 \mathrm{~mL}, 115 \mathrm{mmol})$ in toluene $(50 \mathrm{~mL})$ was treated with $\mathrm{PCl}_{5}(12.53 \mathrm{~g}, 60 \mathrm{mmol})$ at room temperature. After stirring for $30 \mathrm{~min}$, the reaction mixture was heated at 100 ${ }^{\circ} \mathrm{C}$ until no further hydrogen chloride was formed. The reaction mixture was concentrated under reduced pressure and crude product was recrystallized from hexane $/ \mathrm{CH}_{2} \mathrm{Cl}_{2}$ to afford compound 6 as a yellow crystal. mp $100{ }^{\circ} \mathrm{C} ;{ }^{1} \mathrm{H}$ NMR $\left(300 \mathrm{MHz} \mathrm{CDCl}_{3}\right) \delta 7.12(\mathrm{~d}, 4 \mathrm{H}, J=8.5 \mathrm{~Hz}), 7.29$ (t, 2H, $J$ $=6.8 \mathrm{~Hz}), 7.47(\mathrm{t}, 4 \mathrm{H}, J=7.2 \mathrm{~Hz}) ;{ }^{13} \mathrm{C} \mathrm{NMR}(75 \mathrm{MHz}$, $\left.\mathrm{CDCl}_{3}\right) \delta 120.67,126.91,129.28,138.89,146.03$; HRMS $\left(\mathrm{EI}^{+}, m / z\right)$ calcd for $\mathrm{C}_{14} \mathrm{H}_{10} \mathrm{Cl}_{2} \mathrm{~N}_{2} 276.0221$, measured 276.0221 .

Synthesis of $N, N^{\prime}$-Bis(4-methylphenyl)ethanediimidoyl Dichloride (7): A solution of $p$-toluidine (4) (46.24 mmol) and oxalyl chloride $(5)(9.3 \mathrm{~mL}, 98 \mathrm{mmol})$ in toluene $(50$ $\mathrm{mL})$ was treated with $\mathrm{PCl}_{5}(11 \mathrm{~g}, 52 \mathrm{mmol})$ at room temperature. After stirring for $30 \mathrm{~min}$, the reaction mixture was heated at $100{ }^{\circ} \mathrm{C}$ until no further hydrogen chloride was formed. The reaction mixture was concentrated under reduced pressure and crude product was recrystallized from hexane/ $\mathrm{CH}_{2} \mathrm{Cl}_{2}$ to afford compound 7 as a yellow crystal. mp 100 ${ }^{\circ} \mathrm{C} ;{ }^{1} \mathrm{H} \mathrm{NMR}\left(300 \mathrm{MHz}, \mathrm{CDCl}_{3}\right) \delta 2.40(\mathrm{~s}, 6 \mathrm{H}), 7.08(\mathrm{~d}, 4 \mathrm{H}$, $J=8.0 \mathrm{~Hz}), 7.26(\mathrm{~d}, 4 \mathrm{H}, J=7.7 \mathrm{~Hz}) ;{ }^{13} \mathrm{C} \mathrm{NMR}(75 \mathrm{MHz}$, $\left.\mathrm{CDCl}_{3}\right) \delta$ 21.42, 121.09, 129.79, 137.05, 138.07, 143.31; HRMS $\left(\mathrm{EI}^{+}, m / z\right)$ calcd for $\mathrm{C}_{16} \mathrm{H}_{14} \mathrm{Cl}_{2} \mathrm{~N}_{2}$ 304.0534, measured 304.0531.

Synthesis of 3,6-Bis(5-(4-(diphenylamino)phenyl)-2thienyl)-1,4-diphenylpyrrolo[3,2-b]pyrrole-2,5-dione (8): Ester 2 (33.23 $\mathrm{mmol})$ and $1 \mathrm{M} \mathrm{NaN}\left(\mathrm{SiMe}_{3}\right)_{2}(144 \mathrm{mmol})$ was dissolved in THF $(30 \mathrm{~mL})$ at room temperature under argon. After stirring for $1 \mathrm{~h}$, the reaction mixture was cooled to $-78^{\circ} \mathrm{C}$ and a THF solution $(30 \mathrm{~mL})$ of the compound 6 (15.75 mmol) was slowly added. After stirring for $48 \mathrm{~h}$ at room temperature, aqueous solution of $\mathrm{NH}_{4} \mathrm{Cl}(5 \mathrm{M}, 250$ $\mathrm{mL})$ and ethyl acetate $(400 \mathrm{~mL})$ were added. The organic layer was washed with $3 \times 200 \mathrm{~mL}$ of water and concentrated under reduced pressure. The residue was purified by flash column chromatography to give compound $\mathbf{8}$ as a red solid. mp $300{ }^{\circ} \mathrm{C} ;{ }^{1} \mathrm{H}$ NMR (300 MHz, $\left.\mathrm{CDCl}_{3}\right) \delta 5.95$ (d, 2H, $J=$ $4.1 \mathrm{~Hz}), \delta 6.71(\mathrm{~d}, 2 \mathrm{H}, J=3.8 \mathrm{~Hz}), \delta 7.30-7.32(\mathrm{~m}, 4 \mathrm{H}), \delta$ 7.45-7.48 (m, 6H); ${ }^{13} \mathrm{C}$ NMR not obtained due to the low solubility; HRMS $\left(\mathrm{EI}^{+}, m / z\right)$ calcd for $\mathrm{C}_{26} \mathrm{H}_{14} \mathrm{Br}_{2} \mathrm{~N}_{2} \mathrm{O}_{2} \mathrm{~S}_{2}$ 607.8863, measured 607.8865.

Synthesis of 3,6-Bis(5-(4-(diphenylamino)phenyl)-2-thienyl)1,4-bis(4-methylphenyl)pyrrolo[3,2-b]pyrrole-2,5-dione (9): Ester $2(23.12 \mathrm{mmol})$ and $1 \mathrm{M} \mathrm{NaN}\left(\mathrm{SiMe}_{3}\right)_{2}(98 \mathrm{mmol})$ was dissolved in THF $(30 \mathrm{~mL})$ at room temperature under argon. After stirring for $1 \mathrm{~h}$, the reaction mixture was cooled to $-78^{\circ} \mathrm{C}$ and a THF solution $(30 \mathrm{~mL})$ of the compound 7 (10.56 mmol) was slowly added. After stirring for $48 \mathrm{~h}$ at room temperature, aqueous solution of $\mathrm{NH}_{4} \mathrm{Cl}(5 \mathrm{M}, 250 \mathrm{~mL})$ and ethyl acetate $(400 \mathrm{~mL})$ were added. The organic layer was 
washed with $3 \times 200 \mathrm{~mL}$ of water and concentrated under reduced pressure. The residue was purified by flash column chromatography to give compound $\mathbf{9}$ as a red solid. mp 300 ${ }^{\circ} \mathrm{C} ;{ }^{1} \mathrm{H}$ NMR $\left(300 \mathrm{MHz}, \mathrm{CDCl}_{3}\right) \delta 2.44(\mathrm{~s}, 6 \mathrm{H}), 5.99(\mathrm{~d}, 2 \mathrm{H}$, $J=4.1 \mathrm{~Hz}), 6.72(\mathrm{~d}, 2 \mathrm{H}, J=4.1 \mathrm{~Hz}), \delta 7.18$ (d, 4H, $J=8.5$ $\mathrm{Hz}), \delta 7.26(\mathrm{~d}, 4 \mathrm{H}, J=6.3 \mathrm{~Hz}) ;{ }^{13} \mathrm{C} \mathrm{NMR}(500 \mathrm{MHz}$, $\left.\mathrm{CDCl}_{3}\right) \delta 21.25,100.18,109.99,110.00,116.33,126.97$, $129.44,129.79,129.88,130.75,131.16,138.78,142.22$, 170.04; HRMS (FAB, m/z) calcd for $\mathrm{C}_{28} \mathrm{H}_{19} \mathrm{Br}_{2} \mathrm{~N}_{2} \mathrm{O}_{2} \mathrm{~S}_{2}$ 636.9255, measured 636.9255.

Synthesis of the Poly(N-9-heptadecanyl-2,7-carbazolealt-3,6-bis(5-(4-(diphenylamino)phenyl)-2-thienyl)-1,4diphenylpyrrolo[3,2-b]pyrrole-2,5-dione) (P1): Carefully purified 3,6-bis $\{5-[4-($ diphenylamino)phenyl]-2-thienyl $\}-1,4-$ diphenylpyrrolo[3,2-b]pyrrole-2,5-dione (8) (150 mg, 0.25 mmol), 2,7-bis(4',4',5',5'-tetramethyl-1',3',2'-dioxaborolan-2'-yl)$\mathrm{N}$-9"-heptadecanylcarbazole (10) (160 mg, $0.25 \mathrm{mmol})$, and $\left(\mathrm{PPh}_{3}\right)_{4} \mathrm{Pd}(0)(3 \mathrm{~mol} \%)$ were dissolved in a mixture of toluene and aqueous $2 \mathrm{M} \mathrm{K}_{2} \mathrm{CO}_{3}$. The mixture was refluxed with vigorous stirring for 3 days under argon atmosphere. After $72 \mathrm{~h}$, phenylboronic acid was added to the reaction then $12 \mathrm{~h}$ later, bromobenzene was added and the reaction mixture refluxed overnight to complete the end-capping reaction. After cooling to room temperature, the mixture was poured into methanol. The precipitated material was recovered by filtration. The resulting solid material was reprecipitated using $100 \mathrm{~mL}$ of $\mathrm{THF} / 1.0 \mathrm{~L}$ of methanol several times to remove residual amount of catalyst. The resulting polymer was soluble in $\mathrm{THF}, \mathrm{CHCl}_{3}, \mathrm{ODCB}$ and toluene.

Synthesis of the Poly(N-9-heptadecanyl-2,7-carbazolealt-3,6-bis(5-(4-(diphenylamino)phenyl)-2-thienyl)-1,4bis(4-methylphenyl)pyrrolo[3,2-b]pyrrole-2,5-dione) (P2): Carefully purified 3,6-bis $\{5-[4-($ diphenylamino)phenyl]-2thienyl \}-1,4-bis(4-methylphenyl)pyrrolo[3,2-b]pyrrole-2,5dione (9) (150 mg, $0.23 \mathrm{mmol}$ ), 2,7-bis(4',4',5',5'-tetramethyl1',3',2'-dioxaborolan-2'-yl)- $N$-9"-heptadecanylcarbazole (10) (150 mg, $0.23 \mathrm{mmol})$, and $\left(\mathrm{PPh}_{3}\right)_{4} \mathrm{Pd}(0)(3 \mathrm{~mol} \%)$ were dissolved in a mixture of toluene and aqueous $2 \mathrm{M} \mathrm{K}_{2} \mathrm{CO}_{3}$. The mixture was refluxed with vigorous stirring for 3 days under argon atmosphere. After $72 \mathrm{~h}$, phenylboronic acid was added to the reaction then $12 \mathrm{~h}$ later, bromobenzene was added and the reaction mixture refluxed overnight to complete the end-capping reaction. After cooling to room temperature, the mixture was poured into methanol. The precipitated material was recovered by filtration. The result- ing solid material was reprecipitated using $100 \mathrm{~mL}$ of THF/ $1.0 \mathrm{~L}$ of methanol several times to remove residual amount of catalyst. The resulting polymer was soluble in THF, $\mathrm{CHCl}_{3}, \mathrm{ODCB}$ and toluene.

Acknowledgments. This work was supported by the National Research Foundation of Korea (NRF) grant funded by the Korea government (MEST) (No. 2010-0015069) and by Basic Science Research Program through the National Research Foundation of Korea (NRF) funded by the Ministry of Education, Science and Technology (No. 20110010851).

\section{References}

1. Son, H. J.; Wang, W.; Xu, T.; Liang, Y.; Wu, Y.; Li, G.; Yu, L. J. Am. Chem. Soc. 2011, 133, 1885.

2. Song, S.; Jin, Y.; Park, S. H.; Cho, S.; Kim, I.; Lee, K.; Heeger, A. J.; Suh, H. J. Mater. Chem. 2010, 20, 6517.

3. Song, S.; Kim, J.; Shim, J.; Kim, J.; Lee, B. H.; Jin, Y.; Kim, I.; Lee, K.; Suh, H. Sol. Energ. Mat. Sol. C 2012, 98, 323.

4. Duan, C.; Chen, K. S.; Huang, F.; Yip, H. L.; Liu, S.; Zhang, J.; Jen, A. K. Y.; Cao, Y. Chem. Mater. 2010, 22, 6444.

5. Helgesen, M.; Sondergaard, R.; Krebs, F. C. J. Mater. Chem. 2010, 20, 36.

6. Dou, L.; You, J.; Yang, J.; Chen, C. C.; He, Y.; Murase, S.; Moriarty, T.; Emery, K.; Li, G.; Yang, Y. Nat. Photonics 2012, 6, 180.

7. Li, G.; Zhu, R.; Yang, Y. Polymer solar cells. Nat. Photonics 2012 , 6, 153-161 .

8. Park, S. H.; Roy, A.; Beaupre, S.; Cho, S.; Coates, N.; Moon, J. S.; Moses, D.; Leclerc, M.; Lee, K.; Heeger, A. J. Nat. Photonics 2009, 3, 297.

9. Song, S.; Jin, Y.; Kim, S. H.; Moon, J.; Kim, K.; Kim, J. Y.; Park, S. H.; Lee, K.; Suh, H. Macromolecules 2008, 41, 7296.

10. Blouin, N.; Michaud, A.; Leclerc, M. Adv. Mater. 2006, 19, 2295.

11. Bürgi, L.; Turbiez, M.; Pfeiffer, R.; Bienewald, F.; Kirner, H.-J.; Winnewisser, C. Adv. Mater. 2008, 20, 2217-2224.

12. Bijleveld, J. C.; Gevaerts, V. S.; Nuzzo, D. D.; Turbiez, M.; Mathijssen, S. G. J.; de Leeuw, D. M.; Wienk, M. M.; Janssen, R. A. J. Adv. Mater. 2010, 22, E242-E246.

13. Kronemeijer, A. J.; Gili, E.; Shahid, M.; Rivnay, J.; Salleo, A.; Heeney, M.; Sirringhaus, H. Adv. Mater. 2012, 24, 1558.

14. Wuckelt, J.; Doring, M.; Langer, P.; Grrls, H.; Beckert, R. Tetrahedron Lett. 1997, 38, 5269.

15. Langer, P.; Wuckelt, J.; Döring, M. J. Org. Chem. 2000, 65, 729.

16. Song, S.; Ko, S. J.; Shin, H.; Jin, Y.; Kim, I.; Kim, J. Y.; Suh, H. Synth. Met. 2012, 162, 2288.

17. Cho, S.; Seo, J. H.; Kim, S. H.; Song, S.; Jin, Y.; Lee, K.; Suh, H.; Heeger, A. J. Appl. Phys. Lett. 2008, 93, 263301.

18. Fang, Y. K.; Liu, C. L.; Yang, G. Y.; Chen, P. C.; Chen, W. C. Macromolecules 2011, 44, 2604. 